\title{
Research on Collaborative Design of Traffic Network and Landscape Construction on Urban Residential Area
}

\author{
Yao Lin \\ Institute of Tropical Agriculture and Forestry, Hainan University, Haikou, Hainan, 570208
}

\author{
Keywords: Traffic Network, Landscape Construction, Urban Residential
}

\begin{abstract}
With the rapid socio-economic development, residents' income and living standards have been greatly improved private cars began to enter the family. The increase of car ownership leads to the increase of traffic pressure in the residential area, and the traffic problem has a direct impact on the landscape environment in the residential area, which is contradictory to the pursuit of high quality living environment. So how to coordinate the living area of the traffic organization and landscape design contradictions, to create a safe, convenient, beautiful landscape environment, comfortable residential area is our planning designers should consider the important issue.
\end{abstract}

\section{Introduction}

With the rapid popularization of private cars, the impact of motor vehicles on the internal environment of residential areas gradually highlighted, first manifested in the motor vehicle itself to the residential area of the environment to bring the safety and pollution problems, reasonable car road organization in the planning is particularly important, How to rationally organize traffic to the impact of motor vehicles on the residential environment to minimize the impact of road network planning to solve the primary problem; followed by parking problems, many residential areas of the "parking is difficult, difficult to pass" problem. Because the early traffic and parking system planning unreasonable, as well as the lack of research on the relationship between the parking lot and the living environment, making a large number of private cars nowhere to park, the owner can only choose "puncture pin" parking, resulting in green, leisure Square, residential roads and other public space was occupied, seriously affecting the living environment and travel convenience. The other side green area of residential is important to the owner by being important constituent of community quality. In the country's current design specifications, the number and area of residential parking spaces have corresponding indicators, to meet the number of parking spaces designed to occupy the green area; but to ensure adequate green rate, vehicle parking is difficult. Therefore, the traditional parking spaces and green space rate of the shift is also one of the prominent contradictions in residential planning and design.

\section{Traffic Characteristics and Landscape Analysis of Urban Residential Area}

Compared with urban traffic is mainly required to meet the traffic requirements of the vehicle, the traffic in the residential area shows obvious characteristics of life, which is determined by the nature of its land use. In the residential area, the main purpose of residents' traffic trips is to go to get off work, school, commercial shopping and other daily life behavior; living area road is not only the regional links between the various parts of the space, but also people's daily activities of the space carrier. Therefore, the residential area traffic not only requires the provision of convenient and 
accessible traffic conditions, but also the safe and harmonious living space of the residential area is an important part.

In the residential area, in order to ensure the safety of residents travel and reduce the negative impact of traffic on the living environment, residential area traffic planning often take a variety of traffic restrictions, speed restrictions and other physical measures to limit its internal transit traffic. At the same time, because the general residential area within the road network by the city secondary roads, slip roads and the following hierarchical composition, these roads do not require higher traffic as urban traffic.

Compared with the urban traffic, the internal traffic in the residential area is showing the diversity characteristics: First, the residential area is more diversified, which includes the main body of urban traffic (cars, buses, freight vehicles, non-motor vehicles, etc.) and Some special vehicles (disabled cars, trolleys, human tricycles, etc.); Second, the use of more diversified roads, residential areas in addition to residents to meet commuting, school, delivery, garbage and other traffic functions, but also for the municipal Laying the provision of the network to provide the site for the greening and landscaping of the residential area, providing the necessary space for ventilation and lighting. Various functions interspersed in the road space, mutual benefit and mutual influence.

The elements of the landscape of the residential area can be divided into two categories: one is the composition of the material, namely, human, construction, greening, water, courtyard, facilities, essays and other elements; the other is the composition of spiritual culture, Pulse, characteristics and so on.

With the construction of urban residential area of large-scale and integrated, residential area has become a function of the city's "condensed body", its internal living in different levels of residents, and each level of residents of the landscape needs are not The same, which led to the diversity of residential landscape needs. At the same time, the living environment landscape design is to give residents to create leisure, activities, space, even the same level of residents, when the activities of the activities and activities of different intensity, the requirements of the landscape is also different. Such as traffic in the traffic in the people concerned about the landscape is mainly concentrated in the streets of the road and on both sides of the building, and in walking traffic and leisure, people are concerned about the landscape is more concentrated in the courtyard green space, comedy facilities. All of which require residential area landscape design to meet the needs of the region's diverse appreciation and use.

\section{Coordination Analysis of Traffic and Landscape in Urban Residential Area}

Whether it is traffic or landscape, in the residential area have a certain proportion of land use. In our country such a person more and less countries, the rational use of land is placed in front of each planner, policy makers in the first question. According to the Urban Residential Area Planning and Design Code (G B50180-93), the residential area includes residential land, public construction land, road land (all kinds of roads and ground parking lots in the district) and public green areas. Must be balanced with other parts of the land control, must coordinate planning.

Residential traffic and landscape are the use of the needs of diversification of the characteristics, and therefore in different occasions should pay attention to traffic and landscape in the spatial scale of the match. For example, the residential area of the road from the traffic function can be divided into traffic roads (mainly secondary roads and some traffic slip) and the living road (mainly for the living branch and branch below the level of road, see below Residential area road classification), two types of roads in the driving speed on a larger difference, the speed of change has brought people on the landscape elements of the sense of scale changes. In the case of high-speed motion, 
objects with smaller field of view are neglected in the flies, and the spatial scale of the landscape elements is required to be increased accordingly. When the low-speed motion, the field of view and the recognition distance are increased, the landscape elements Delicate, meticulous, attract people's attention.

Safety is the most basic requirement of the living environment. In the residential area landscape design, must be closely integrated with the traffic requirements, eliminate security risks, to ensure travel safety. The conflict between landscape design and travel safety is mainly manifested in: the internal traffic path and the living road in the residential area are different in terms of design speed and traffic volume. The safety requirements are different, and the landscape design must be related to road safety The requirements are consistent. The rapid growth of the number of residential motor vehicles has led to the increasing traffic on the roads of the residential areas. To ensure the safety of traffic, it is necessary to carry out careful traffic organization design. At the same time, the road landscape as a residential area of a major part of the landscape, but also the focus of residential landscape design. Both must be closely integrated to ensure that residents travel safely, convenient and comfortable. The landscape-based traffic design mainly includes the layout of the cross-section of the residential area, the widening design of the traffic lights control intersection, and the requirements of the line of sight.

Study on the Coordination Design of Traffic Organization and Landscape Construction in Residential Area

In the initial stage of the planning and design of the residential area, the landscape design company must be selected at the same time so that the landscape of the landscape can be arranged as soon as possible. In the process of intervening, the landscape designer can arrange the outdoor space structure, road design and parking facilities, Fire system settings and other issues to provide reasonable advice and guidance to make up for planners due to limited professional knowledge of the lack of landscape considerations.

Reasonable handling of the relationship between architectural design and landscape design is conducive to improving the environmental quality and landscape utilization. In this process, the architectural design should take full account of the landscape factors. First, the introduction of the external landscape should be considered in the architectural design process, such as the construction of the undercarriage, the entrance, the sink and the lighting courtyard, and the intersection of the building and the outdoor environment.

For the firefighting, traffic organization, parking, entrances and exits, vertical relations and so on affect the landscape design of the larger restrictive conditions, Party A landscape management staff should be with the previous department, building planning and design units to optimize the direction of landscape design efforts to Faster time to find the right integrated design direction, and in the task book to be determined to avoid unnecessary rework. Communication and coordination, and the need for clear content includes these aspects: building layout, elevation system and building fire map; car traffic, parking arrangements, the basement area, the basement lighting, ventilation wells range, location and mode; , The organization of the people, the specific layout of the booth; planning need to reserve the central space, the use of the landscape axis, the spatial structure of the landscape treatment and other requirements. The communication and coordination of these contents and reached - to the views of the latter if the amendment should be timely and timely communication and coordination.

The landscape designer shall submit relevant opinions on the design tasks provided by Party A and the relevant basic design materials, and communicate with the planners and architects to understand the design concept and style of the planning, and inquire carefully the issue of the 
deduction, Analysis of the possibility of changes in the design conditions, a clear prerequisite for landscape design.

Landscape architects submit to the architects the basic information about the basement, main structure, and equipment design that may affect the design of the landscape, including swimming pools, overhead floors, sink gardens, roof gardens, structures, water features, fireways, garage trees Position, design form, and should consult with each other. And the construction of the junction of the surface should be responsible for the landscape design, such as a variety of outdoor steps, all kinds of ramp eleven underground garage ramp, bicycle ramp, barrier ramp, fire ramp, air defense entrance, Outdoor safety railing, lighting wells, ventilation wells, garbage room, all kinds of outdoor box finishes optimization. Planning, architecture, landscape design team should be more communication, communication, coordination, construction, planning design concepts and style of communication, and landscape designers to discuss those restrictive design conditions to optimize the processing options and the possibility of changes in the field Sex. At the same time to deal with fire approval requirements, parking approval requirements, green area approval requirements, the main car road network respect, outdoor box and lighting wells and other outdoor equipment location, the location of the entrance booth, pedestrian flow line organization, moving Line layout and other conditions and information to confirm the coordination.

\section{Conclusion}

With the rapid development of urban residential area construction, the rapid growth of residents' motor vehicle and the increasing demand for living quality, the integration of traffic system and its landscape function in residential area is designed in modern residential area design. It is particularly important. Firstly, it analyzes the traffic characteristics and landscape requirements of urban residential areas, and then studies some contradictions in the process of urban and residential traffic and landscape design, and puts forward the principles, methods and contents of urban residential area traffic and landscape coordination design.

\section{References}

[1] Zhao Xin, Zhou Guoyan. Study on the Dwelling of Residential Area Parking - Taking Hefei Residential Area as an Example [J]. Home Science and Technology, 2010 (11)

[2] Lin Chen. Automobile and residential area environment design [J]. Sichuan Architecture, 2010 (04)

[3] Dou Ri, Liu Guangdi. Residential area parking space and green space combination [J]. Management Manager, 2010 (11)

[4] Hu pattern, Zhang Wei, Lin Zhongyu. Concept and mode of residential planning in foreign countries [J]. International Urban Planning, 2007 (04)

[5] Huang Jiming. With the integrated transport planning [J]. Transportation and Transportation, $2003(06)$ 